\section{Lifestyle Risk Factors Associated with Cases of Myocardial Infarction, Reported in Abbottabad, Haripur and Mansehra Districts}

Sir,

In 2004 , WHO unraveled that IHD causes $12.2 \%$ of worldwide deaths, being the highest cause of deaths in high and middle income countries, while only second to lower respiratory tract infections in low income countries. 1 Thus in order to completely understand occurrence of the condition and its causative factors in our region, we conducted a research in three districts of Hazara Division, i.e. Abbottabad, Haripur and Mansehra. In this study, all the patients admitted in coronary care units of Ayub Teaching Hospital Abbottabad, $\mathrm{CMH}$ Abbottabad, DHQ Haripur, and Benazir Bhutto Shaheed Teaching Hospital Abbottabad, were interviewed to find out prevalence of not only various types of $\mathrm{Ml}$, but also that of lifestyle-associated risk factors of the disease in the aforementioned districts.

Two hundred and ninety six patients with diagnosis of MI were studied, of which $15.5 \%$ were labelled NSTEMI, while others were cases of STEMI. Among these, 52\% were cases of anterior wall $\mathrm{Ml}$, which is globally the most common type and carries the worst prognosis. ${ }^{2}$ Among the cases, $73 \%$ were males, about $80 \%$ were married and $49.2 \%$ were uneducated. Nearly half of the affected had sedentary lifestyle which approves previously documented $12.2 \%$ attributable risk of the disease related to lack of physical activity.3,4 Majority, i.e. $68.6 \%$ of the consulted patients, were diagnosed cases of hypertension; whereas, only about one-third were known diabetics. These figures are in concordance to not only the international figures but regional statistics, as well. 4,5 Data collected also revealed that $40 \%$ of the cases were addicted to smoking cigarettes or some other form of tobacco, and majority preferred fat in their diet. These too, showed that regional figures are similar to international indices previously stated. 4,5
Myocardial Infarction is a deadly disease, having significantly high case fatality rate. But as most common risk factors of the condition are related to lifestyle, very minute adjustment in daily life can produce a huge impact in fighting the disease. Thus general population should be educated about the epidemiology and natural history of the disease so that they should themselves make adjustment to their daily life habits and standards.

Another important factor that does not seem to be directly affecting the incidence, thus so often ignored, is educational level of the society. As our research was carried out in a society not very well educated in comparison to modern civilisation, depicted the fact very precisely. Thus education and awareness are the most important factors in settling the future dynamics of this deadly disease in our society.

\section{REFERENCES}

1. World Health Organization (2008). The global burden of disease: 2004 update. Geneva: World Health Organization.

2. Rose M. Coughlin RM. Attacking anterior-wall myocardial infarction in time. [Online]. Available from: URL:http:// www.americannursetoday.com/attacking-anterior-wallmyocardial-infarction-in-time-2, 2014

3. Lee IM, Shiroma EJ, Lobelo F, Puska P, Blair SN, Katzmarzyk PT. Effect of physical inactivity on major non-communicable diseases worldwide: An analysis of burden of disease and life expectancy. Lancet 2012; 380:219-29.

4. Yusuf S, Hawken S, Ounpuu S, Dans T, Avezum A, Lanas F, et al. Effect of potentially modifiable risk factors associated with myocardial infarction in 52 countries (the inheret study): casecontrol study. Lancet 2004; 364:937-52.

5. Umar H, Mattiullah K, Nasir HSK, Nasir A, Rabnawaz, Waqar AM, et al. Frequency of newly diagnosed diabetes mellitus in patients with acute myocardial infarction. J Ayub Med Coll Abbottabad 2014; 26:368-70.

Muhammad Usama, Yasir Basir, Shoaib Irshad and Saad Muhammad

Department of Pediatrics, Ayub Teaching Hospital, Abbottabad, Pakistan

Correspondence: Dr. Muhammad Usama, Department of Pediatrics B Ward, Ayub Teaching Hospital, Abbottabad, Pakistan

E-mail: muhammadusama137@gmail.com

Received: July 02, 2018; Accepted: September 14, 2018 